\title{
Response to Rituximab in Non-Hodgkin Lymphoma Patients at National Oncology Center, Aden, Yemen, 2017-2020: Retrospective Cohort Study
}

Magdi Aldaeri ( $\nabla$ magdid14@gmail.com )

Yemen Field Epidemiology Training Program

Gamal Abdul Hamid

National Program of Cancer Control

Mohammed Al Amad

Yemen Field Epidemiology Training Program

Yasser Ghaleb

Yemen Field Epidemiology Training Program

\section{Research Article}

Keywords: Non-Hodgkin lymphoma, CHOP, Rituximab, Survival, Yemen

Posted Date: February 15th, 2022

DOI: https://doi.org/10.21203/rs.3.rs-1351140/v1

License: () (1) This work is licensed under a Creative Commons Attribution 4.0 International License. Read Full License 


\section{Abstract}

Background: Rituximab is currently approved for the treatment of relapsed and refractory indolent lymphomas, which was added to the protocol in Yemen although it was highly costly. The study aimed to determine the long-term response of rituximab on Non-Hodgkin Lymphomas (NHL) patients.

Methods: A retrospective cohort study was conducted in the National Oncology Center (NOC) in Aden by review of medical registries for NHL patients from 2017-2020. Sociodemographic and clinical data were extracted from patients' files by a well-trained team. SPSS version 23 was used for the analysis of data, and Kaplan Meier survival curve was used to measure overall survival (OS) and progression-free survival (PFS) between two groups CHOP (cyclophosphamide, doxorubicin, vincristine, and prednisolone) and rituximab-CHOP group in two follow up periods (12-months and 4-years). Cox regression was used to evaluate the association between the risk factors. A P-value of $<0.05$ at a confidence interval of $95 \%$ is considered statistically significant.

Results: Of 100 patients, 50 for each group of $\mathrm{CHOP}$ and R-CHOP. The under 60 years represented $70 \%$. Advanced Stage represented $64 \%$ and diffuse large B cell lymphoma represented $47 \%$ of all subtypes of NHL. Significant association difference in OS in two periods of follow-up (12-month and 4-years) for CHOP vs. R-CHOP was $63 \%$ vs. $86 \%$, and $10 \%$ vs. $33 \%$, respectively ( $P=0.01$ and $P=0.04)$. In contrast, the difference was non-statically significant in the PFS in two periods $39 \%$ vs. $66 \%$, and $12 \%$ vs. $27 \%$ for CHOP vs. R-CHOP, respectively $(P=0.10$ and $P=0.31)$. The age group $>60$ years, $\geq 6$ cycles of chemotherapy received, abnormality of $\mathrm{LDH}$, and married patients were the significantly hazard proportion that was associated with poor prognostic factors $(P=0.009$, $0.001,0.010$, and 0.011 , respectively).

Conclusion: The addition of rituximab to CHOP chemotherapy had a statistical difference in overall survival and there is no difference in PFS. Elderly, married patients, more than 6 cycles of chemotherapy received, and abnormality of LDH were the most important prognostic factors. Therefore, providing the oncology center with Rituximab for ongoing use of NHL patients especially those under 60 years, further assessment for hospital-related risk factors that lead to decreased survival are recommended.

\section{Background}

Non-Hodgkin lymphoma (NHL) is an aggressive chronic lymphoproliferative disorder of the immune system that comprises many subtypes, each with distinct epidemiology, etiology, histology, immunophenotypic, genetic, clinical features; and responses to therapy, which can make diagnosis difficult. B-cell NHLs represented almost all of the cases $85 \%$, while T/Natural killer cells represented $15 \%$ [1].

Anaplastic large cell, follicular, B cell lymphoma, diffuse large cell, lymphoblastic, mantle cell, mycosis fungoides, primary CNS lymphoma, and cutaneous Tcell lymphoma are the subtypes of NHL. Furthermore, it may result from chromosomal translocations, infections, environmental factors, immunodeficiency states, and chronic inflammation [2].

In 1982, the NHL was classified by morphology and clinical behavior (i.e., low, intermediate, or high grade). Then in1990s, the Revised European-American Lymphoma (REAL) classification attempted to apply immunophenotypic and genetic features in identifying distinct clinicopathologic NHL entities [3]. The World Health Organization (WHO) classification divided NHL into those of B-cell origin and those of T-cell and natural killer (NK)-cell origin according to the REAL approach [4].

The treatment of non-Hodgkin lymphoma (NHL) varies greatly, depending on many factors: Tumor stage, Phenotype (B-cell, T-cell or Natural Killer cell/nullcell), Histology (i.e., low, intermediate, or high grade), Symptoms, Performance status, Patient age, Comorbidities [5].

Rituximab is a monoclonal antibody that targets the CD20 antigen, which is expressed on the surface of pre-B and mature B-lymphocytes. Rituximab binds to CD20 after mediates B-cell lysis (or breakdown). The possible mechanisms of cell lysis include complement-dependent cytotoxicity and antibody-dependent cell-mediated cytotoxicity [6].

$\mathrm{NHL}$ is the most prevalent hematopoietic neoplasm, representing approximately $4.3 \%$ of all cancer diagnoses and ranking seventh in frequency among all cancers. The incidence of NHL has increased 168\% since 1975 (while survival has improved by 158\%) [7].

Globally, the latest GLOBOCAN data in 2018 estimated 509,600 new cases of NHL were diagnosed; comprising $2.8 \%$ of worldwide cancer diagnoses and the age-standardized risk of NHL was 6.7 among men and 4.7 among women. In addition, an estimated 248,700 deaths were attributable to NHL, and the NHL's 5year survival from 2010 to 2016 in the US was $72.7 \%$ [7].

In the Eastern Mediterranean region EMRO, 2020, according to GLOBOCAN, the NHL represented as the eighth rank of all cancer in the region, incidence rate of $4.2 \%$, and case mortality rate of $3.4 \%$, the prevalence of 5 -years $10.68 / 100,000$ of the population [8].

In Yemen, Non-Hodgkin Lymphoma was a major health problem that represents the second most common type of cancer (10.1\%) in males, and the third common type in females (6.6\%) in 2011 [9]. In Aden governorate, the NHL represented the first common hematological malignancy in 2010 [10]. In 2013 , Lymphoma represented $9.8 \%$ of all cancer patients who attended the national oncology center, and the NHL represented $65 \%$ of all lymphomas patients [11].

Rituximab entered into the protocol of NHL in NOC, although of its higher cost, there is no previous study published in Yemen and neighboring countries to measure the impact and response of it on lymphomas patients. The present study aims to determine the long-term response of rituximab on $\mathrm{NHL}$ patients and measure the survival rate among patients when treated with R-CHOP or $\mathrm{CHOP}$.

\section{Methods}




\section{Study design}

A retrospective cohort study was conducted during the period of (2017-2020).

\section{Study area and Setting}

The study was conducted in the National Oncology Center (NOC), Aden governorate. NOC was established in 2013 at Alsadaqa hospital. The majority of attendees to the center are from Aden governorate and many neighboring Governorates such as Lahj, Abian, Aldhale, Shabowh, and other governorates. The number of tumor cases until October 2021 reached 8960 cases for the center, where the number of males reached 3157 cases, females 4303 , and children 1550 , with an increase of cases in the last years. In addition, the center receives approximately 1200 cases annually.

\section{Study Population}

All the Non-Hodgkin lymphoma patients that registered in NOC from 2017-2020 and received at least four cycles of R-CHOP\& CHOP protocol were included in this study.

\section{Definitions and selection criteria}

Exposed cases were defined as all lymphoma patients $>16$ years in NOC received at least four cycles of R-CHOP protocol [1] and lymphoma patients > 16 years in NOC received at least four cycles of $\mathrm{CHOP}$ protocol were defined as non-exposed.

\section{Inclusion criteria:}

Patients with NHL received at least four cycles of R-CHOP protocol or CHOP, the age more than 16 years and diagnosed between $2017-2020$ years.

\section{Exclusion criteria:}

The patient received less than four cycles of chemotherapy (R-CHOP and $\mathrm{CHOP}$ ) or received other protocols than $\mathrm{R}-\mathrm{CHOP}$ or $\mathrm{CHOP}$ protocol or both protocols of R-CHOP and CHOP. In addition, patients with age less than 16 years or diagnosed before 2017 and after 2020.

\section{Data collection tools and procedures}

We reviewed patients' registries and files in NOC by a trained team (principal investigator \& data collectors). Abstracting form used to collect all variables of the patient files regarding patients' demographics (e.g., sex, age, job, place of birth, marital status) and clinical features such as stage of disease, a subtype of $\mathrm{NHL}$, B symptoms, and outcomes. In addition, the abstracting form included data about date of diagnosis, start chemotherapy, follow up, lack of follow up, death, negative scan, and relapse for each patient as well as laboratory investigations

Quality assurance and control

The principal investigator monitored all the processes of data collection from patient registries and each sample of the abstracting forms was evaluated to be sure that collection is done perfectly as instructed in training. Data collected from all collectors and frequencies were used to check data before data entry

Data entry and management

Data entered in the excel format of the abstracting form and exported into SPSS version 23 for analysis. Univariate and multivariate cox regression analysis was conducted with the final model. Secondary clinical indicators assessed at the end of chemotherapy protocols were overall survival (OS) is the percentage age of people who can still live for a definite time after they were clinically diagnosed with a certain disease like cancer or started therapy for that disease. Progression-free survival (PFS), The PFS is the period during treatment and after the management of a malignant disease like cancer, patient lives with the disease but it does not get worse. That measured from date of diagnosis to date of relapse or progression of the lesion or death.

Kaplan Meier survival curve analyses were employed to measure OS and PFS for the two groups of cases (CHOP/ R-CHOP) to find any difference in response due to treatment protocols. A P-value of less than 0.05 at a confidence interval of $95 \%$ is considered statistically significant.

\section{Results}

\section{Descriptive analysis}

A total of 200 cases of NHL were admitted at NOC-Aden in the last four years, 100 cases of them were well-matched to inclusion and exclusion criteria of this study, of whom 50 cases were treated according to CHOP and 50 cases with R-CHOP. The overall mean age of patients was 48.8 years ( \pm 16 ). Table 1 shows the characteristics of $\mathrm{NHL}$ patients, aged less than 60 years, male, non-employed, and Married patients formed the majority of cases, $70 \%, 57 \%, 61 \%$ and $81 \%$, 


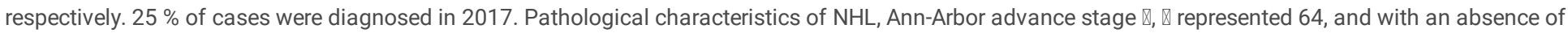
B-symptoms (fever, drenching night sweats, and loss of more than 10 percent of body weight over 6 months) in $67 \%$ of cases. Nodal lesion represented $54 \%$ and diffuse large B cell lymphoma (DLBCL) represent $47 \%$ of all NHL subtypes, (66\% in R-CHOP group). 
Table 1

Characteristics of Non-Hodgkin lymphoma patients related to protocol, NOC-Aden, Yemen 2017-2020

Variables Total $n=100 \quad$ CHOP $n=50 \quad$ R-CHOP $n=50 \quad$ P-Value

\begin{tabular}{|c|c|c|c|c|}
\hline . & Frequency & Percent & Frequency Percent & Frequency Percent \\
\hline
\end{tabular}

$\leq 60 \quad 30(70) \quad 34(49) \quad 36(51)$

$>60 \quad 30(30) \quad 16(53) \quad 14(47)$

$\begin{array}{ll}\text { sex } & 1.000\end{array}$

Male 57(57) 29(51) 28(49)

$\begin{array}{llll}\text { Female } & 43(43) & 21(49) & 22(51)\end{array}$

Job

Employed

Not- Employed

39(39)

$31(51) \quad 30(49)$

Marital state

61(61)

Single

Married

19(19)

12(63)

7(37)

LDH

81(81)

38(47)

43(53)

Normal 38(38)

Abnormal

62(62)

21(55)

0.40

B2M

29(47)

17(45)

33(53)

Normal

Abnormal

39(39)

24(62)

0.06

WBC

61(61)

26(43)

15(38)

35(57)

Normal

$84(84)$

44(52)

0.27

Abnormal

16(16)

6(38)

40(48)

CD20

Positive

67(67)

17(25)

N/A

Negative

33(33)

33(100)

0.16

Bone marrow

95(95)

49(52)

1(20)

Infiltrated

5 (5)

15(56)

4(80)

Diagnosed years

27(27)

2017

2018

26(26)

20(77)

6(23)

2019

2020

21(21)

9(43)

12(57)

26(26)

6(23)

20(77)

Sub-type of NHL

DLBCL

Unclassified B-cell

Follicular

Other B-cell

T-cell

NK cell

47(47)

16(34)

31(66)

29(29)

20(69)

9(31)

13(13)

5(38)

8(62)

4(4)

2(50)

2(50)

B-Symptoms

Page 5/11 


\begin{tabular}{|c|c|c|c|c|}
\hline Present & 33(33) & $14(42)$ & $19(58)$ & 0.28 \\
\hline Absent & $67(67)$ & $36(54)$ & $31(46)$ & \\
\hline Stages of NHL & & & & 0.03 \\
\hline$\bigotimes-\bigotimes$ & $36(36)$ & $23(64)$ & $13(36)$ & \\
\hline$\bigotimes-\bigotimes$ & $64(64)$ & $27(42)$ & $37(58)$ & \\
\hline Lesion site & & $29(54)$ & $25(46)$ & 0.54 \\
\hline Nodal & $54(54)$ & & & \\
\hline Extra-nodal & $46(46)$ & $21(46)$ & $25(54)$ & \\
\hline Chemotherapy Cycle & & & & 0.21 \\
\hline$<6$ & $35(35)$ & $21(60)$ & $14(40)$ & \\
\hline$\geq 6$ & $65(65)$ & $29(45)$ & $36(55)$ & \\
\hline Outcome & & & & 0.02 \\
\hline Alive & $80(80)$ & $35(44)$ & $45(56)$ & \\
\hline Died & $20(20)$ & $15(75)$ & $5(25)$ & \\
\hline
\end{tabular}

The abnormality of laboratory investigations of LDH $62 \%$, B2M $61 \%$, while normality of WBC $84 \%$ and bone marrow $95 \%$. Positive cases for CD20 represent $67 \%$.

Advanced stages of disease and mortality were found to be significantly associated with patients who were treated with $\mathrm{CHOP}$. ( $p=0.03$ and $p=0.02)$, respectively.

\section{Survival analysis}

Two periods to follow up with the patients in our study were determined. First, the patients of NHL during four years were followed up every 12 months; from the date of diagnosis to the end period for each group (CHOP \& R-CHOP). The overall survival (OS) for 12-month for $\mathrm{CHOP}$ and R-CHOP was $63 \%$ and $86 \%$, respectively with a p-value of $(P=0.01)$. While the progression-free survival $(\mathrm{PFS})$ for the same period was $39 \%$ and $66 \%$ for $\mathrm{CHOP}$ and $\mathrm{R}-\mathrm{CHOP}$ respectively with a p-value $(P=0.10)$ (Figure 1$)$.

Second, the patients were followed up for four years, the overall survival (OS) for CHOP and R-CHOP was with little difference $10 \%$ and $33 \%$, respectively with $\mathrm{P}$-value $(P=0.04)$. While progression-free survival (PFS) during four years follow-up was $12 \%$ and $27 \%$ for $\mathrm{CHOP}$ and $\mathrm{R}$ - $\mathrm{CHOP}$ respectively with $\mathrm{P}$-value $(P=$ 0.31) (Figure 2)

Table 2 illustrates the hazard proportion in many characteristics of patients by using cox regression. The age group more than 60 years, more than 6 cycles of chemotherapy, abnormality of $\mathrm{LDH}$, and married patients were the significantly hazard proportion that was associated with poor prognostic factors with $\mathrm{P}$ value of $0.009,0.001,0.010$, and 0.011 , respectively. 
Table 2

\section{Cox proportion hazard of Non-Hodgkin lymphoma cases, NOC-Aden, Yemen}

\begin{tabular}{|c|c|c|c|}
\hline Variables & Hazard Ratio & 95\% C.I. & P-Value \\
\hline Treatment protocol (CHOP \& R-CHOP) & 2.554 & $0.914-7.133$ & 0.0736 \\
\hline Age group $(\leq 60 \&>60)$ & 2.927 & $1.132-7.566$ & 0.009 \\
\hline B-symptoms (Yes \& No) & 1.804 & $0.814-3.995$ & 0.1461 \\
\hline B2M (Normal \& Abnormal) & 1.244 & $0.550-2.814$ & 0.6009 \\
\hline Bone marrow ( Normal \& Infiltrated) & 0.000 & NA & NA \\
\hline CD20 (Positive \& Negative) & 1.363 & $0.452-4.109$ & 0.5822 \\
\hline Chemotherapy cycle $(<6 \& \geq 6)$ & 0.040 & $0.012-0.131$ & 0.000 \\
\hline LDH (Normal \& Abnormal) & 3.508 & $1.342-9.166$ & 0.0105 \\
\hline Marital state (Single \& married) & 4.973 & $1.438-17.194$ & 0.0113 \\
\hline Sex (Male \& Female) & 0.467 & $0.183-1.193$ & 0.1115 \\
\hline 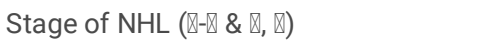 & 0.988 & $0.423-2.307$ & 0.9779 \\
\hline WBC (Normal \& Abnormal) & 0.585 & $0.141-2.421$ & 0.4591 \\
\hline
\end{tabular}

\section{Discussion}

The burden of the NHL has increased distinctly in the last years in Yemen. In patients with NHL, the addition of rituximab to standard treatment significantly enhanced response to therapy and overall outcomes. Rituximab is currently approved for the treatment of relapsed and refractory indolent lymphomas as single-agent therapy and as initial therapy in combination with standard chemotherapy regimens [12].

$\mathrm{NHL}$ is most often diagnosed in an elderly patient that is aged $>60$ years, but there is an exception for some types of $\mathrm{NHL}$ that are diagnosed in an adult patient [13]. Our study showed the mean age of the patient was 48 years, which is similar to the previous study conducted in Aden, Hadramoot governorates [10,14], and other studies in China and Mexico $[1,15]$. This is due to our patients being contained in all subtypes of NHL.

Regarding gender, our study showed no great difference between males and females (57\%). This result is consistent with previous studies in Southeastern governorates of Yemen, Saudia Arabia, and Mexico [1, 16-18]. In contrast, studies conducted in Yemen, and among Chinese patients showed that females more than males, $[14,15]$ this attributed to the male developing disease more likely than females [19].

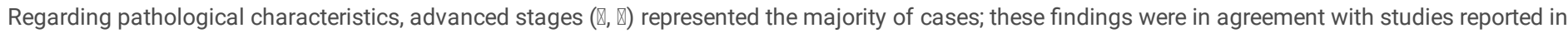
Saudia Arabia, Mexico, and France $[1,18,20,21]$. On other hand, a study in China revealed that most cases were in stages $\otimes, \otimes[15]$. This difference may be due to the lack of early screening of disease in our country.

About $30-40 \%$ of NHL patients complain of B-symptoms at the time of diagnosis [5]. our finding revealed that two-thirds of patients did not complain of Bsymptoms (67\%), which is nearly similar to studies conducted in Mexico and Korea that were $(65 \%, 68 \%)$ respectively, and higher than reported from Saudia Arabia $(52 \%)[1,18,22]$.

Cervical lesions represent $28 \%$ of all cases in the first of other lesion sites, agrees with a study conducted in Hadramoot [14], and different with a study conducted in Aden which revealed the common lesion was in the abdomen [17].

Diffuse large B cell lymphoma was the most frequent subtype of $\mathrm{NHL}$ in our study; this result is similar to a study conducted in Hadramoot Yemen, Aseer Saudia Arabia, and a previous study Middle East region $[14,18,23]$. This is due to DLBCL being the most common form of lymphoma that represents about $30 \%$ of $\mathrm{NHL}[24]$.

Regarding laboratory investigations, our study showed the abnormality of LDH and B2M in most cases, this finding was agreed with a study conducted in Korea [22], and disagreed with the findings of a study conducted in China. [15] In addition, most cases were a normal count of WBC; a similar result was reported in Saudia Arabia [18]. and CD20 was positive in $67 \%$ of patients in our study, which is lower than findings from Saudia Arabia $82 \%$ [18]. This difference may be due to variances in sample size, and the percentage of B cell lymphoma that contains about $98 \%$ of positive CD20. Furthermore, Only $5 \%$ of cases had bone marrow infiltration, which is consistent with findings reported in a previous study [22].

The incidence rate of new cases of non-Hodgkin lymphoma was $19.6 / 100,000$ per year and the death rate was $5.3 / 100,000$ per year globally, furthermore, the mortality was about fourth of diagnosed cases of $\mathrm{NHL}$ [25]. Our study found that the overall fatality rate was $20 \%$ and $30 \% \& 10 \%$ for $\mathrm{CHOP}$ and R-CHOP, respectively, which is close to the global rate. This result is slightly lower than a study conducted in Korea that found the overall fatality rate was $31 \%$ and $57 \% \& 14 \%$ for each group, and another study in France showed $35 \%$ and $(41 \% \& 29 \%)[20,22]$.

In this study, the survival outcome of two groups (CHOP\& R-CHOP) was estimated in two follow-up periods in 12 months and 4-year, according to previously evaluated cancer survival analysis [26]. Our findings revealed that the overall survival (OS) in 12-month was $63 \%$ and $86 \%$, for $\mathrm{CHOP}$ and R-CHOP respectively. 
This was nearly similar to a study conducted in China for the same period 12-month (75\%\& 93.8\%) [27]. In addition, the progression-free period (PFP) in our study was $39 \%$ and $66 \%$ for $\mathrm{CHOP}$ and R-CHOP, respectively, lower than studies conducted in China ( $52.8 \% \& 81.2 \%$ ) [27]. This could be due to many causes such as the low quality of medical services in Yemen compared with other countries, decrease patient outcomes that lead to poor regular follow-up, and most patients coming in advanced stages.

The survival rate has been improving since 1997, thanks to treatment advances. From 2009 to 2018, the death rate decreased by $2 \%$ annually. The overall 5 year survival rate for people with $\mathrm{NHL}$ is $73 \%$ [28]. The 4-years survival rate for patients in our study was $10 \%$ and $33 \%$ for overall survival of $\mathrm{CHOP}$ and $\mathrm{R}$ CHOP groups, respectively. This result was much lower than 5-years survival in the United States (73\%), a study conducted in Mexico (61.8\% \& $65 \%)$, and in Korea $(94.7 \%$ \&84.7\%) $[1,28,29]$. on the other hand, the progression-free survival (PFS) was $12 \%$ and $27 \%$ for $\mathrm{CHOP}$ and R-CHOP, respectively. This is also much lower than other studies conducted in Mexico (63.8 and 51.2\%), Korea (50.0\% vs. $79.0 \%)$, and Germany $(59 \%$ \& $79 \%)$ [1,22, 30].

Our finding revealed significant overall survival (OS) of two groups and not significant progression-free survival (PFS), this was consistent with the previous study conducted in China and France that found significant overall survival $[15,20]$. In contrast, previous studies conducted in Korea found significant progression-free survival and not significant overall survival, and another study conducted in Mexico found no significance for both overall and progressionfree survival $[1,22]$. This difference may be due to the most patients were in advanced stages.

The prognosis for non-Hodgkin lymphoma ( $\mathrm{NHL}$ ) varies with the histology, the stage of disease at diagnosis, and the response of the disease to therapy. Furthermore, age $\geq 60$ years, elevated lactate dehydrogenase (LDH) level, Stage III or IV disease, Eastern Cooperative Oncology Group (ECOG) performance status $\geq 2$, and two or more extra-nodal sites [13]. In our study, the significant prognostic factors were the age $>60$ years, $>6$ cycles chemotherapy, abnormality of $\mathrm{LDH}$, and married patient with P-value $<0.05$. This conforms to studies conducted in Korea and China that found age $>60$ years were poor prognostic factors $[15,22]$. In contrast, many studies conducted in different countries found these factors not significantly associated with protocol treatment $[1,20,29]$. The main limitation in our study was the poor documentation for some processes of treatment of patients and the follow-up results. Lack of a computerized system in the treatment center leads to a lack of the outcome of many patients.

In conclusion, the addition of rituximab to CHOP chemotherapy had a statistical difference in overall survival and there is no difference in PFS. Elderly, married patients, more than 6 cycles of chemotherapy received, and abnormality of LDH were the most important prognostic factors. Therefore, providing the oncology center with Rituximab for ongoing use of NHL patients especially those under 60 years, further assessment for hospital-related risk factors that lead to decreased survival are recommended.

\section{Abbreviations}

B2M: Beta 2 microglobulin; CBC: Complete Blood Cell; CHOP: cyclophosphamide, doxorubicin, vincristine, and prednisone; CNS: Central Nervous System; CT: Computerized tomography; DFS: Disease-free survival; EFS: Event-free survival; GLOBOCAN: Global Cancer Observative; LDH: Lactate Dehydrogenase; NOC: National Oncology Center; NHL: Non-Hodgkin Lymphoma; NK: Nature Killer; OS: Overall survival; PFS: Progression-free survival; R: Rituximab; REAL: Revised European-American Lymphoma; US: United State; WHO: World Health Organization; Y-FETP: Yemen- Field Epidemiology Training Program.

\section{Declarations}

\section{Acknowledgments}

The authors would like to acknowledge the Training Programs in Epidemiology \& Public Health Interventions Network (TEPHINET) and Yemen Field Epidemiology Training Program for their technical support. In addition, the National Oncology Center, Aden facilitate all process of data collection.

\section{Authors' contributions}

MA the principal investigator, collect data, analyzed it, and wrote the manuscript. GA field supervisor. MA revised data analysis. YG general supervisor of the study, all authors approved the final draft of the study.

\section{Corresponding author}

Correspondence to Magdi Saif Aldaeri.

\section{Funding}

This work was supported by TEPHNET; the funder had a role only in data collection

\section{Availability of data and materials}

All relevant data are presented in this paper, and more information can be provided upon reasonable request from the corresponding author. 


\section{Ethics approval and consent to participate}

Study submitted to the Ethical Committee at the Ministry of Public Health\& Population (MoPHP) for approval (at 18.8.2021, accepted at 31.8.2021, reference number 5146). Authorization for conducting the study in NOC was obtained from Aden Health Office and the director of the NOC. As well as patient's confidentiality secured using a unique ID. The study did not involve experiments on a human subject or human participants under the age of 18 years.

\section{Consent for publication}

This study does not include any identifiable human images or data and thus does not require consent to publish.

\section{Competing interests}

The author(s) declared no potential conflicts of interest concerning the research, authorship, and/or publication of this article.

\section{Author Details}

1 Yemen Field Epidemiology Training Program, Sana'a, Yemen. 2 National Program of cancer control, Aden, Yemen

\section{References}

1. Jaime-Pérez JC, Gamboa-Alonso CM, Vázquez-Mellado de Larracoechea A, Rodríguez-Martínez M, Gutiérrez-Aguirre CH, Marfil-Rivera LJ, et al. NonHodgkin lymphomas: impact of rituximab on overall survival of patients with diffuse large B-cell and follicular lymphoma. Archives of medical research. 2015;46(6):454-61.

2. Armitage JO, Gascoyne RD, Lunning MA, Cavalli F. Non-hodgkin lymphoma. The Lancet. 2017;390(10091):298-310.

3. Singh R, Shaik S, Negi BS, Rajguru JP, Patil PB, Parihar AS, et al. Non-Hodgkin's lymphoma: A review. Journal of Family Medicine and Primary Care. 2020;9(4):1834.

4. Hennessy BT, Hanrahan EO, Daly PA. Non-Hodgkin lymphoma: an update. The lancet oncology. 2004;5(6):341-53.

5. Sanjay Vinjamaram M, MPH; Chief Editor: Emmanuel C Besa, MD. Non-Hodgkin Lymphoma (NHL) Feb 25, 2021. Available from: https://emedicine.medscape.com/article/203399-overview\#showall.

6. DrugBank. Rituximab 2021. Available from: https://go.drugbank.com/drugs/DB00073.

7. Thandra KC, Barsouk A, Saginala K, Padala SA, Barsouk A, Rawla P. Epidemiology of Non-Hodgkin's Lymphoma. Medical Sciences. 2021;9(1):5.

8. WHO. Global Cancer Observation 2020 [updated 11/7/2021]. Available from: https://gco.iarc.fr/today/online-analysis-table? $v=2020 \&$ mode=cancer\&mode_population=continents\&population=900\&populations=900_993\&key=asr\&sex=0\&cancer=39\&type=2\&statistic=5\&prevalenc group-1-2-3.

9. Bawazir AA. Cancer incidence in Yemen from 1997 to 2011: a report from the Aden cancer registry. BMC Cancer. 2018;18(1):540.

10. Hamid GA. The Pattern of Hematological Malignancies at Al-Gamhouria Teaching Hospital, Aden, Yemen, from 2008 to 2010. Turkish Journal of Haematology. 2012;29(4):342.

11. Eman Abdullah Larde, Ashwal AAA. Lymphomas Cancer Registry Data Analysis Report, National Oncology Center $2012-2013$ 2013 [cited 2021 ]. Available from:http://www.yfetp.com/.

12. Dotan E, Aggarwal C, Smith MR. Impact of Rituximab (Rituxan) on the Treatment of B-Cell Non-Hodgkin's Lymphoma. P \& T : a peer-reviewed journal for formulary management. 2010;35(3):148-57.

13. Mohammad Muhsin Chisti M, FACP; Chief Editor: Emmanuel C Besa, MD. B-Cell Lymphoma Apr 27, 2021. Available from: https://emedicine.medscape.com/article/202677-overview\#a6.

14. Humam M, Al-Nakhbi N, Melkat A, Almontaser T, Binnabhan A. Malignant lymphoma in Hadhramout Sector, Yemen: a retrospective study of 170 cases classified according to the WHO classification. Journal of Current Medical Research and Practice. 2016;1(2):6-11.

15. Huang Y, Ye S, Cao Y, Li Z, Huang J, Huang H, et al. Outcome of R-CHOP or CHOP regimen for germinal center and nongerminal center subtypes of diffuse large B-cell lymphoma of Chinese patients. TheScientificWorldJournal. 2012;2012:897178.

16. Abdul Hamid G. MALIGNANT LYMPHOMA IN SOUTHEASTERN of YEMEN. TJH. 2000;18.

17. BALQIS AL-SAYEED ABDULLA EBRAHIM MD, AHMED SALEH OMER AL-GEFRI, M.D., NASSER ALBISHI MD, AHMED MUTHANNA. Patterns of Malignant Lymphoma among Admitted Patients inAl Gamhoria Hospital, Aden, Yemen. The Medical Journal of Cairo University. 2021;89(March):175-9.

18. Alyahya N, Adiga B, Alwadei A, Alshahrani G, Alyahya F. The clinico-pathological profile of non-Hodgkin's lymphoma in Aseer region of Saudi Arabia. BMC Research Notes. 2019;12(1):418.

19. Cancer.Net. Lymphoma - Non-Hodgkin: Risk Factors 2021. Available from: https://www.cancer.net/cancer-types/lymphoma-non-hodgkin/risk-factors.

20. Coiffier B, Lepage E, Briere J, Herbrecht R, Tilly H, Bouabdallah R, et al. CHOP chemotherapy plus rituximab compared with CHOP alone in elderly patients with diffuse large-B-cell lymphoma. The New England journal of medicine. 2002;346(4):235-42. 
21. Rauf MS, Akhtar S, Maghfoor I. Changing trends of adult lymphoma in the Kingdom of Saudi Arabia - comparison of data sources. Asian Pacific journal of cancer prevention : APJCP. 2015;16(5):2069-72.

22. Ahn HK, Kim SJ, Yun J, Yi JH, Kim JH, Won YW, et al. Improved treatment outcome of primary mediastinal large B-cell lymphoma after introduction of rituximab in Korean patients. International journal of hematology. 2010;91(3):456-63.

23. Yaqo RT, Jalal SD, Ghafour KJ, Hassan HA, Hughson MD. Non-Hodgkin Lymphoma in the Middle East Is Characterized by Low Incidence Rates With Advancing Age. Journal of Global Oncology. 2019(5):1-10.

24. Cancer.Net. Lymphoma - Non-Hodgkin: Subtypes 2021. Available from: https://www.cancer.net/cancer-types/lymphoma-non-hodgkin/subtypes.

25. INSTITUTE NC. Cancer Stat Facts: Non-Hodgkin Lymphoma 2021. Available from: https://seer.cancer.gov/statfacts/html/nhl.html.

26. Schemper M, Smith TL. A note on quantifying follow-up in studies of failure time. Controlled clinical trials. 1996;17(4):343-6.

27. Wu HJ, Zhang QY, Chen DF, Guan XJ, Zhang BL, Ma J. [Comparison of rituximab plus CHOP regimen and CHOP regimen alone for treatment of newly diagnosed patients with diffuse large B-cell lymphoma]. Ai zheng = Aizheng = Chinese journal of cancer. 2005;24(12):1498-502.

28. Board CNE. Lymphoma - Non-Hodgkin: Statistics 2021. Available from: https://www.cancer.net/cancer-types/lymphoma-non-hodgkin/statistics.

29. Sohn BS, Kim SM, Yoon DH, Kim S, Lee DH, Kim JH, et al. The comparison between CHOP and R-CHOP in primary gastric diffuse large B cell lymphoma. Annals of hematology. 2012;91(11):1731-9.

30. Pfreundschuh M, Trümper L, Osterborg A, Pettengell R, Trneny M, Imrie K, et al. CHOP-like chemotherapy plus rituximab versus CHOP-like chemotherapy alone in young patients with good-prognosis diffuse large-B-cell lymphoma: a randomised controlled trial by the MabThera International Trial (MInT) Group. The Lancet Oncology. 2006;7(5):379-91.

\section{Figures}

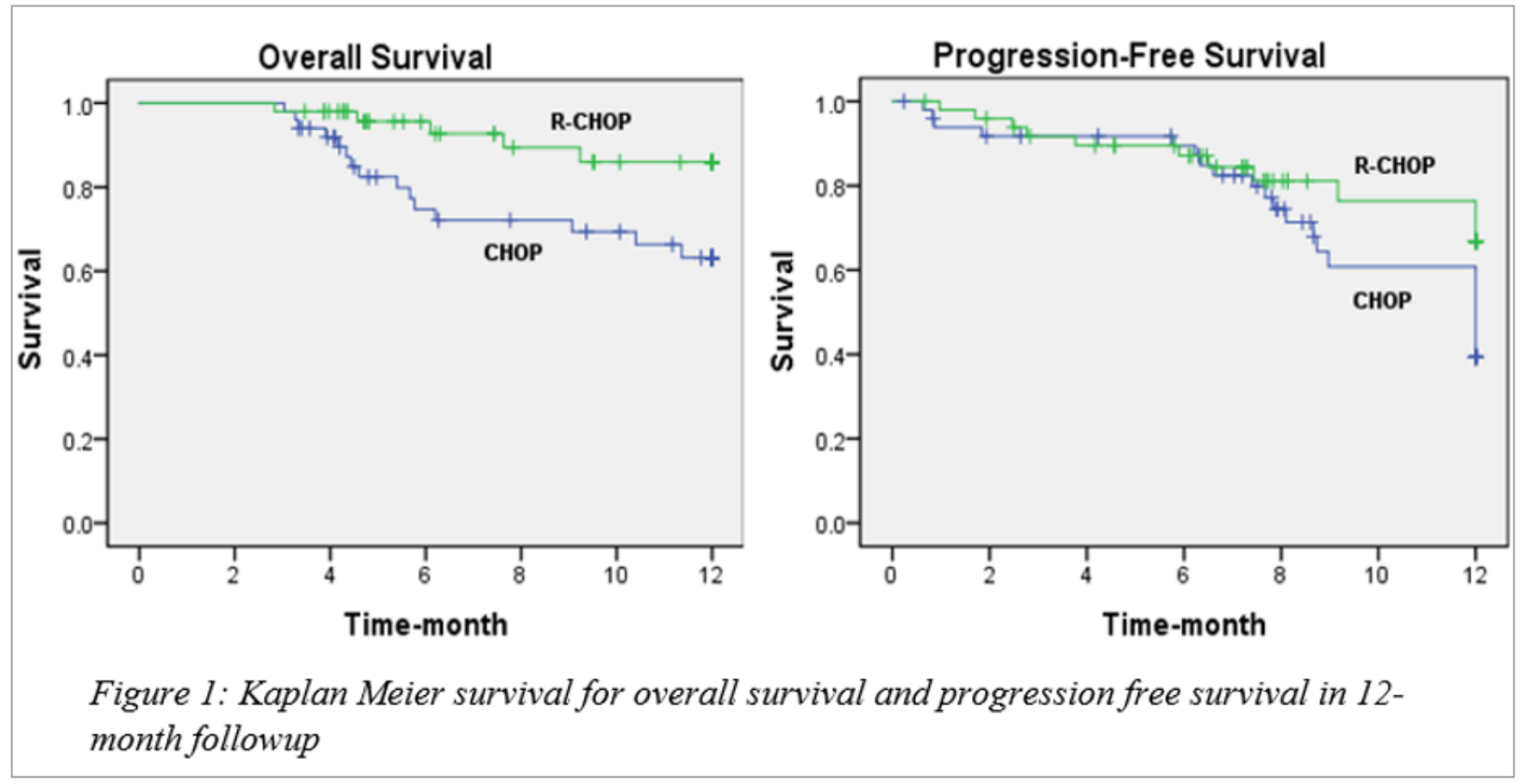

Figure 1

Please See image above for figure legend. 


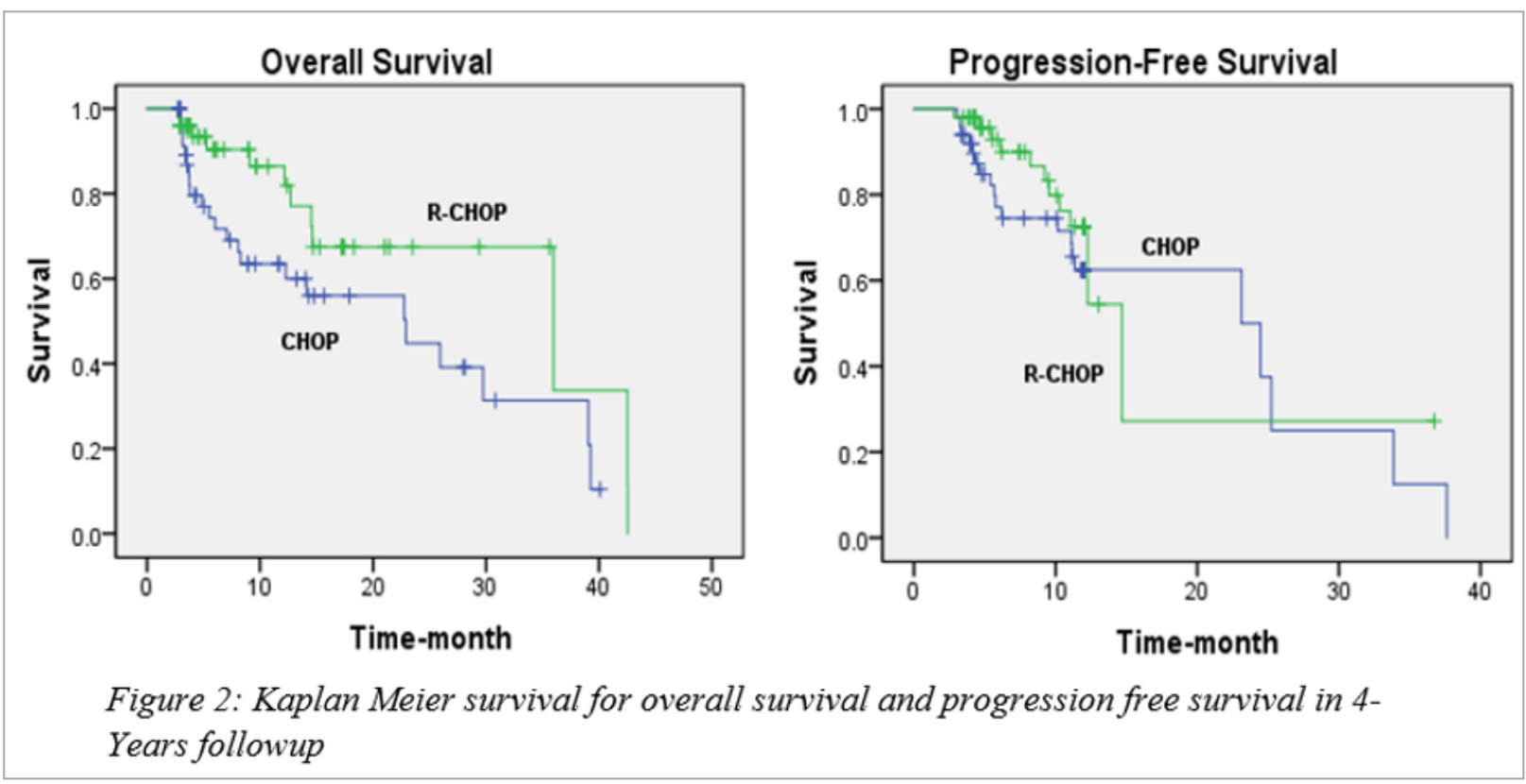

Figure 2 